\title{
Nonlinear response of axially functionally graded Timoshenko beams on elastic foundation under harmonic excitation
}

https://doi.org/10.1515/cls-2019-0008

Received Nov 11, 2018; accepted Dec 27, 2018

Abstract: Forced vibration of non-uniform axially functionally graded (AFG) Timoshenko beam on elastic foundation is performed under harmonic excitation. A linear elastic foundation is considered with three different classical boundary conditions. AFG materials are an advanced class of materials that have potential for application in various engineering fields. In the present work, variation of material properties along the longitudinal axis of the beam are considered according to power-law forms. Five values of material gradation parameter provides different functional variation and their effect on the frequency response of the system is studied. The present approximate method is displacement based and Von-Karman type of geometric nonlinearity is considered with rotational component to incorporate transverse shear. Hamilton's principle is used to derive nonlinear set of governing equation and Broyden method is implemented to solve the nonlinear equations numerically. The results are successfully validated with previously published article. Frequency vs. amplitude curve corresponding to different combinations of system parameters are presented and are capable of serving as benchmark results. A separate free vibration analysis is undertaken to include backbone curves with the frequency response curves in the non-dimensional plane.

Keywords: AFG beam, Timoshenko beam, non-uniform beam, geometric non-linearity, large amplitude vibration

\footnotetext{
*Corresponding Author: Sarmila Sahoo: Department of Civil En-
gineering, Heritage Institute of Technology, Kolkata-700107, India;

^Corresponding Author: Sarmila Sahoo: Department of Civil En
gineering, Heritage Institute of Technology, Kolkata-700107, India; Email: sarmila.sahoo@gmail.com, sarmila_ju@gmail.com Hareram Lohar, Anirban Mitra: Department of Mechanical Engineering, Jadavpur University, Kolkata-700032, India
}

๑ Open Access. (c) 2019 H. Lohar et al., published by De Gruyter. (Cc) BY License

\section{Introduction}

Axially functionally graded (AFG) materials are a category of inhomogeneous materials, which are obtained by continuous and functional gradation of material properties along the axial/longitudinal direction. These materials can handle critical situations with unequal distribution of mechanical, thermal or chemical loadings. By virtue of their non-uniform distribution, they can adjust the static deflection to not exceed a threshold value, buckling load to not fall below a pre-specified level and/or natural frequencies either less than or exceeding a pre-defined range. Hence, it is natural to expect the usage and application of AFG materials to grow in the near future. Already, they find applications in civil, mechanical, aerospace and aeronautical engineering owing to their capability to improve distribution of weight and strength, and to ensure structural integrity.

It is understood that the most general kind of spatial functional gradation involves property variations along multiple axes. In case of a beam, such functional grading combines both the axial and thickness direction [1-5]. However, such an analysis involves added complexities in formulation and mathematical treatment. So, it is unsurprising to find that the majority of research work deal with study of FG beams having thickness direction gradation only [6-11]. On the other hand, research effort devoted to AFG beams is quite limited and only recently researchers have taken interest into this domain. Various approaches have been adopted for investigating the static/buckling and dynamic behaviours of non-uniform AFG beams on the basis of Euler-Bernoulli beam model [12-21].

However, in the Euler-Bernoulli beam theory, the effects of rotary inertia and shear deformation are neglected. For this reason, in case of sufficiently thick beams the model always overestimates the analysis outcomes, for example, the frequency response in forced vibration analysis. Hence, the Timoshenko beam theory [22] has to be employed to effectively analyse systems with large thickness. There are only a few studies in the literature con- 
cerning modelling and analysis of AFG beams on the basis of Timoshenko beam theory. Shahba et al. [23] introduced a new beam element and studied the free vibration and buckling behaviour on AFG tapered Timoshenko beams through FE approach. Huang et al. [24, 25] presented a unified approach to investigate free vibration and buckling behaviours of AFG Timoshenko non-uniform beams. Rajasekaran [26] adopted differential transformation method and differential quadrature element method of lowest order to perform free vibration analysis of rotating AFG Timoshenko tapered beams considering four first order differential equations. Sarkar and Ganguli [27] obtained closed form solution for free vibration of AFG Timoshenko beams with uniform cross-section, having clamped-clamped boundary condition. Calim [28] used complementary functions method and modified Durbin's algorithm to study transient behaviour of AFG Timoshenko tapered beams. Shafiei et al. [29] performed free vibration analysis on a rotary AFG micro-beam on the basis EulerBernoulli and Timoshenko beam theories using generalized differential quadrature method and compared the results of the two beam theories. Chen et al. [30] conducted free vibration analysis on a nanoparticle carrying $\mathrm{AFG}$ nano-cantilevers with an emphasis on the effect of mass and rotational inertia of the nanoparticle. Ghayesh [31] performed nonlinear forced vibration study of AFG Timoshenko tapered beams. Recently, Huang et al. [32] studied the free vibration a spinning AFG Timoshenko beam. A spectral-Tchebychev method was employed to solve the dynamic properties of the beam and finally, the effect of AFG material on critical speeds and whirling frequencies was obtained.

Interaction of FGM beam and elastic foundation is another important aspect of structural analysis. In fact, such interactions between elastic media and transversely functionally graded structures have received long-term attentions and have been explored quite frequently [33-41]. However, on this issue, significantly lesser number of papers are found to deal with AFG beams. Only a few articles are available in literature relating to elastic foundation supported AFG thin beams, where Euler-Bernoulli theory is utilised for mathematical formulation of the problem. Huang and Luo [42] presented a new and simple method to calculate the critical buckling loads of beams with axial inhomogeneity on elastic foundation, whereas, Lohar et al. [43-45] investigated the dynamic behaviour of AFG beam on elastic foundation. Research work in the field of AFG Timoshenko beam is extremely rare. Calim [46] analysed free and forced vibrations of AFG Timoshenko beams on two-parameter viscoelastic foundation. Complementary functions method was utilized to solve the differential equations in Laplace domain and modified Durbin's algorithm was applied to transform the results into the time domain.

Considering the above discussion, it is clear that behaviour of AFG Timoshenko beams on elastic foundation is a relatively unexplored research domain. But, keeping in mind that the uses and application of axially graded materials are likely to increase, a thorough study of such materials is essential. Hence, the present study is focussed to analyse forced vibration response of the above-mentioned axially graded system under harmonic excitation. Hamilton's principle is employed to formulate the problem. In the present study, the problem is solved by considering an indirect approach where the dynamic system is reduced to a static case by assuming force equilibrium condition at maximum deformation or at peak load. Only steady-state response is presented by assuming frequency of response of the undamped system is equal to that of the external excitation. The effect of the material gradation along the axis of the beam is studied along with effect of variation in foundation stiffness, taper parameter and length to thickness ratio. Operational deflection shape (ODS) of the system under vibration are also studied.

\section{Mathematical formulation}

A non-uniform AFG beam of length $L$, width $b$ and variable thickness $t(x)$, is considered for analysis in the present paper and it is shown schematically in figures 1 along the $x, y$ and $z$ coordinate directions. Linear tapering of thickness in the axial direction from the root $\left(t_{0}\right)$ to the other end $\left(t_{1}\right)$ is considered. The decrement in thickness takes place according to the expression, $t(x)=t_{0}(1-\alpha x / L)$, while width of the beam remains constant as shown in figures 1 . In the present formulation, the beam is considered to be supported on elastic foundation of stiffness, $K_{f}$. It is important to note that the foundation behaviour is assumed to be linear. Hence, the system is idealized as a series of linear springs which are attached at the bottom face of the beam as shown in Figure 1(a).

The present work considers continuous variation of graded material properties along the beam length ( $x$-axis). In the present work variation of elastic modulus and density are taken into account. These material properties are assumed to vary as a function of the axial coordinate according to the following power-law forms.

Elastic modulus, $E(x)=E_{0}+\left(E_{1}-E_{0}\right)(x / L)^{n}$

Density, $\rho(x)=\rho_{0}+\left(\rho_{1}-\rho_{0}\right)(x / L)^{n}$ 


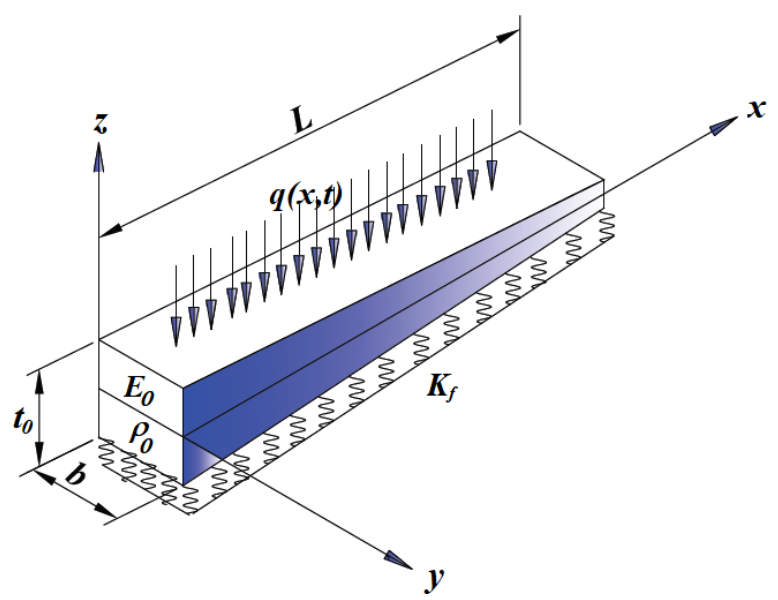

(a)
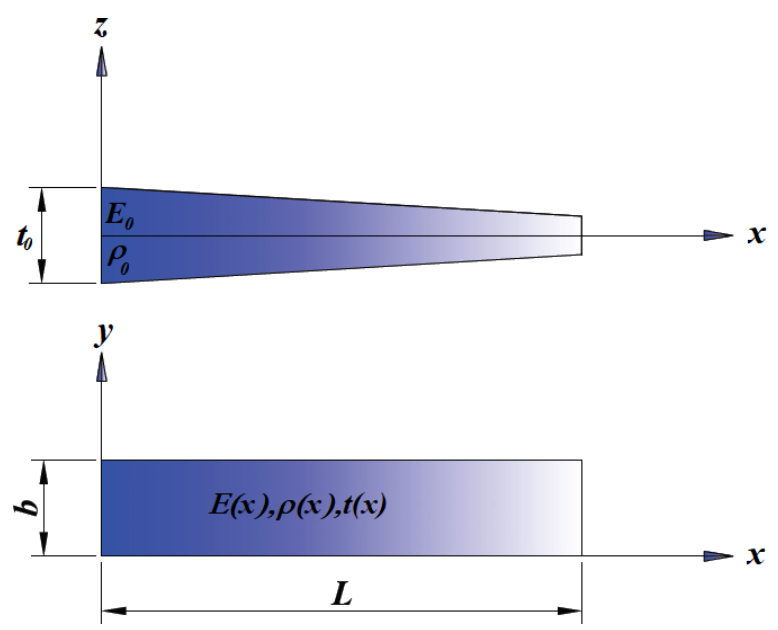

(b)

Figure 1: Beam on elastic foundation (a) Isometric view (b) Orthographic view

Here, $n$ is the gradient parameter describing volume fraction change of both constituents involved. Poisson ratio $(\mu)$ is taken as constant throughout the entire analysis. In order to have a better weight distribution, material properties are gradually increased from the root side $\left(E_{0}\right.$ and $\left.\rho_{0}\right)$ to the other end of the beam $\left(E_{1}\right.$ and $\left.\rho_{1}\right)$, considering opposite distribution to the thickness variation.

Three different classical boundary conditions i.e. clamped-clamped (CC), clamped-simply supported (CS) and simply supported-simply supported (SS) are selected. In-plane boundary conditions are assumed as immovable. The beam is subjected to uniformly distributed transverse time varying excitation, $q(x, t)$ as shown in Figure 1(a). The expression of the external excitation is given by, $q=$ $\bar{q}(x) e^{j \omega \tau}$, where $\omega$ is the frequency of excitation, $j=\sqrt{ }-1$, $\bar{q}$ represents the intensity of the harmonic excitation per unit length of the beam and $\tau$ is the time.

\subsection{Energy expressions}

The present work is a displacement based approximate analysis. Here, displacement fields are assumed and substituted in appropriate energy formulation to obtain the system governing equations as functions of certain unknown parameters. Hence, it is important to express the energy functionals, such as strain energy $(U)$, potential energy of the external excitation $(V)$ and kinetic energy $(T)$ in terms of the unknown displacement fields. In order to obtain the strain energy expression of the beam following strain-displacement relations [22] for axial strain $\left(\epsilon_{\text {axial }}\right)$ and shear strain $\left(\epsilon_{\text {shear }}\right)$ are considered,

$$
\begin{gathered}
\varepsilon_{\text {axial }}=\frac{1}{2}\left(\frac{d w}{d x}\right)^{2}+\frac{d u}{d x}-z \frac{d \psi}{d x} \\
\varepsilon_{\text {shear }}=\frac{1}{2}\left(\frac{d w}{d x}-\psi\right)
\end{gathered}
$$

Here, $w, u$ and $\psi$ are transverse, in-plane and rotational displacement fields, respectively. The rotational displacement field is taken into account in the above expression to incorporate the shear deformation and rotary inertia effect. Equation (1) is nonlinear in nature and first two terms together represent von Karman type nonlinear strain-displacement relation. All the displacement fields are functions of axial coordinate and are defined at the mid-plane of the beam.

It is important to note that, in the present study, total strain energy in the system includes the strain energy of the beam as well as foundation $\left(U_{\text {foundation }}\right)$. On the other hand, strain energy of the beam again comprises of two components, strain energy due to axial strain $\left(U_{\text {axial }}\right)$ and strain energy due to shear strain $\left(U_{\text {shear }}\right)$. As a result, total strain energy can be expressed as follows: $U=U_{\text {axial }}+$ $U_{\text {shear }}+U_{\text {foundation }}$.

Substituting the strain-displacement relations (Equations (1) and (2)), the strain energies, $U_{\text {axial }}, U_{\text {shear }}$ and $U_{\text {foundation }}$, can be expressed as follows,

$$
\begin{gathered}
U_{\text {axial }}=\frac{1}{2} \int_{0}^{L} \int_{A}\left[\begin{array}{c}
\frac{1}{4}\left(\frac{d w}{d x}\right)^{4} \\
+\left(\frac{d u}{d x}\right)^{2}+\frac{d u}{d x}\left(\frac{d w}{d x}\right)^{2} \\
-z \frac{d \psi}{d x}\left(\frac{d w}{d x}\right)^{2} \\
-2 z \frac{d u}{d x}\left(\frac{d \psi}{d x}\right) \\
+z^{2}\left(\frac{d \psi}{d x}\right)^{2}
\end{array}\right] E(x) d A d x \\
U_{\text {shear }}=\frac{k_{\text {sh }}}{8} \int_{0}^{L} \int_{A}^{L}\left[\left(\frac{d w}{d x}\right)^{2}+\psi^{2}-2 \psi\left(\frac{d w}{d x}\right)\right] G(x) d A d x
\end{gathered}
$$




$$
U_{\text {foundation }}=\frac{1}{2} \int_{0}^{L} K_{f} w^{2} d x
$$

Here, $k_{s h}$ is shear correction factor which is taken as 5/6 for rectangular cross-section of the beam. $G(x)$ is the shear modulus and expressed as, $G(x)=E(x) / 2(1+\mu)$ and $A(x)$ is the variable cross-section of the beam. It should be noted that in equations (3) and (4), the material property terms appear within the integration, thus taking care of the variations along the axial direction.

It is advantageous to carry out the numerical computations in a normalised domain. Hence, the physical domain is converted to a normalised one by introducing the parameter $\xi(=x / L)$. In the normalized domain, the strain energies are expressed as follows,

$$
\begin{gathered}
U_{\text {axial }}=\frac{1}{2 L} \int_{0}^{1}\left\{\begin{array}{c}
\frac{1}{4 L^{2}}\left(\frac{d w}{d \xi}\right)^{4}+\left(\frac{d u}{d \xi}\right)^{2} \\
+\frac{1}{L}\left(\frac{d w}{d \xi}\right)^{2} \frac{d u}{d \xi}
\end{array}\right\} E(\xi) A(\xi) d \xi \\
+\frac{1}{2 L} \int_{0}^{1}\left(\frac{d \psi}{d \xi}\right)^{2} E(\xi) I(\xi) d \xi \\
U_{\text {shear }}=\frac{k_{\text {sh }}}{2} \int_{0}^{1}\left\{\frac{1}{L}\left(\frac{d w}{d \xi}\right)^{2}-2 \frac{d w}{d \xi} \psi\right. \\
\left.+L \psi^{2}\right\} G(\xi) A(\xi) d \xi \\
U_{\text {foundation }}=\frac{L}{2} \int_{0}^{1} K_{f} w^{2} d \xi
\end{gathered}
$$

The expression for the total potential energy $(V)$ due to externally applied transverse harmonic excitation is given as,

$$
V=L \int_{0}^{1} q w d \xi
$$

Here, $q$ represents uniformly distributed type of excitation. It is important to note that the present formulation has flexibility to handle other type of mathematically expressible loading patterns in equation (9) with minor changes in the formulation.

Kinetic energy of the present dynamic system is expressed as,

$$
T=\frac{1}{2} \int_{0}^{L} \int_{A}\left[\left(\frac{d w}{d t}\right)^{2}+\left(\frac{d u}{d t}\right)^{2}+z^{2}\left(\frac{d \psi}{d t}\right)^{2}\right] \rho(x) d A d x
$$

Here, $\rho(x)$ is the mass density of the beam. In the normalized domain $(\xi=x / L)$, it can be expressed as follow,

$$
\begin{aligned}
T & =\frac{L}{2} \int_{0}^{1}\left\{\left(\frac{d w}{d \tau}\right)^{2}+\left(\frac{d u}{d \tau}\right)^{2}\right\} \rho(\xi) A(\xi) d \xi \\
& +\frac{L}{2} \int_{0}^{1}\left(\frac{d \psi}{d \tau}\right)^{2} \rho(\xi) I(\xi) d \xi
\end{aligned}
$$

\subsection{Forced vibration analysis}

The present formulation is carried out following energy method where Hamilton's principle has been adopted for deriving the governing differential equations of the system. The formulation is based on Timoshenko beam theory, where, shear deformation and rotary inertia effect is taken into account. In the present system geometric nonlinearity is incorporated by considering nonlinear straindisplacement relations. It is assumed that the system exhibits dynamic equilibrium at maximum amplitude of excitation which implies that at this point of time there exist no unbalanced forces in the dynamic system. This unique assumption converts the dynamic problem to static one.

Hamilton's principle, whose mathematical form [22] is provided below, is utilized to derive the governing set of equations.

$$
\delta\left(\int_{\tau_{1}}^{\tau_{2}}(T-U-V) d \tau\right)=0
$$

Here, $\delta$ is the variational operator, $T$ is the kinetic energy of the system, $U$ is the total strain energy stored in the system, $V$ is the work done by the external loading/excitation and $\tau$ is the time. The expressions for these energy functionals $(U, V$ and $T)$ are furnished in the previous section (equations (6), (7), (8), (9) and (11)). From the expressions it is noticeable that all the energy functionals are dependent on the displacement fields. In these expressions $w$, $u$ and $\psi$ are dynamic displacement fields which are completely separable by space and time. They are assumed as linear combinations of orthogonal admissible functions, $\varphi_{i}, \alpha_{i}$ and $\beta_{i}$ and a set of unknown coefficients $\left(d_{i}\right)$ as follows,

$$
\begin{aligned}
& w(\xi, \tau)=\sum_{i=1}^{n w} d_{i} \phi_{i}(\xi) e^{j \omega \tau} \\
& u(\xi, \tau)=\sum_{i=1}^{n u} d_{n w+i} \alpha_{i}(\xi) e^{j \omega \tau} \\
& \psi(\xi, \tau)=\sum_{i=1}^{n s i} d_{n w+n u+i} \beta_{i}(\xi) e^{j \omega \tau}
\end{aligned}
$$


Table 1: Start functions for assumed displacement fields

\begin{tabular}{cccc}
\hline Displacement field & \multicolumn{3}{c}{ Start Function } \\
\cline { 2 - 4 } & $C C$ & $C S$ & $S S$ \\
\hline$w$ & $\varphi_{1}=(x / L)\{1-(x / L)\}$ & $\varphi_{1}=(x / L)\{1-(x / L)\}$ & $\varphi_{1}=(x / L)\{1-(x / L)\}$ \\
$u$ & $\alpha_{1}=(x / L)\{1-(x / L)\}$ & $\alpha_{1}=(x / L)\{1-(x / L)\}$ & $\alpha_{1}=(x / L)\{1-(x / L)\}$ \\
$\psi$ & $\beta_{1}=\sin (\pi x / L)$ & $\beta_{1}=\sin (\pi x / 2 L)$ & $\beta_{1}=\cos (\pi x / L)$ \\
\hline
\end{tabular}

$\omega$ is the response frequency of the vibratory system, $j=$ $\sqrt{ }-1$ and $\tau$ is the time. $n w, n u$ and $n s i$ are the number of orthogonal functions for each of the displacement fields $w, u$ and $\psi$, respectively. Appropriate start functions for these orthogonal set of functions $\left(\varphi_{1}, \alpha_{1}\right.$ and $\left.\beta_{1}\right)$ must be selected to satisfy the flexural, in-plane and rotational boundary conditions of the beam. These start functions must also be continuous and differentiable within the domain. In Table 1, the selected start functions for each of the displacement fields are shown for different boundary conditions. These start functions are used to generate the higher order functions (upto $n w / n u / n s i$ ) implementing Gram-Schmidt orthogonalization scheme [18].

Substituting the appropriate energy expressions and displacement fields into equation (12), the governing equation is obtained as follows:

$$
[K]\{d\}-\omega^{2}[M]\{d\}=\{f\}
$$

Here, $[K]$ is the stiffness matrix, $[M]$ is mass matrix, $\{f\}$ is load vector and $\{d\}$ is the vector of unknown coefficient, respectively. The dimension of these matrices and vectors is $(n u+n w+n s i)$. The elements of $[K],[M]$ and $\{f\}$ are provided separately in the Appendix. It is noteworthy that the stiffness matrix contains terms with unknown coefficients, thus making it nonlinear. As a result, the governing set of equations as represented by equation (14) is nonlinear in nature as well.

An indirect method, in which the dynamic problem is reduced to an equivalent static problem, is adopted to solve nonlinear set of equations. The unknown coefficients are calculated for given amplitude of excitation and excitation frequency. The analysis assumes that at the peak excitation amplitude value the system satisfies the force equilibrium condition. The solution technique adopted in this analysis is one of the multidimensional quasi-Newton methods known as Broyden's method [47]. In this method the Jacobian is calculated on the basis of an initial guess and its value is updated in the successive iterations.

\subsection{Determination of backbone curves}

Backbone curve provides valuable insight about nonlinear behaviour of the systems along with significant information about degree of nonlinearity in the response. It can also be thought of as zero amplitude response of the system. So, it may be useful to study the behaviour of the backbone curve in relation to the frequency response curves in the non-dimensional plane. To obtain the backbone curve, a free vibration study is necessary. However, the study is conducted in two distinct steps. First, the deflected configuration along with the maximum amplitude of deflection is obtained by static analysis. Subsequently, free vibration study is conducted as an eigenvalue problem on the previously obtained deflected configuration. The objective is to identify the loaded natural frequencies. Consequently, the backbone curves are obtained by presenting loaded natural frequencies vs. maximum deflection amplitude plot in non-dimensional frequency-amplitude plane.

\subsubsection{Static analysis}

Principle of minimum total potential energy is utilized to formulate the static analysis, mathematically expressed as,

$$
\delta(U+V)=0
$$

The expression of the energy functionals $U$ and $V$ remain identical to those presented in section 2.1. It is important to note that the external load is purely static in nature unlike the forced vibration case and time varying load component is eliminated. The assumed displacement fields in the static analysis are also made independent of time varying component by removing the temporal part $\left(e^{j \omega \tau}\right)$ in equations (13). The sets of orthogonal admissible functions remain unchanged and are same as the force vibration analysis. Now, properly substituting the energy functionals along with assumed displacement fields, the set of governing equations for the static problem is obtained in the form given below:

$$
[K]\{d\}=\{f\}
$$


The elements of $[K]$ and $\{f\}$ are identical to those of the previously explained forced vibration analysis. In the static analysis, the solution of the set of nonlinear equations is achieved using an iterative scheme following direct substitution method and the deflected configuration of the system is obtained.

\subsubsection{Free vibration analysis}

Hamilton's principle, as given by equation (12) is utilized to formulate the small amplitude free vibration problem. The expressions of $T$ and $U$ are already furnished in section 2.1 and remain unchanged, whereas, the term $V$ reduced to zero. This is due to the reason that the free vibration study is conducted on the deflected shape of the beam whose static solution has been previously obtained. The dynamic displacements are assumed as linear combination of space and time functions as shown previously in forced vibration analysis. However, for free vibration analysis, $\omega$ denotes the natural frequency of the vibratory system and $d_{i}$ s are the new set of unknown coefficients different from static analysis. $\varphi_{i}, \alpha_{i}$ and $\beta_{i}$ have the identical form as the static and as well as the forced vibration problem. After proper substitution of energy functionals along with the assumed dynamic displacement field, the set of governing equations for the free vibration problem is obtained in the form given below:

$$
[K]\{d\}-\omega^{2}[M]\{d\}=0
$$

The obtained equation represents a standard eigenvalue problem, solution to which is obtained by using Matlab's intrinsic solver. Loaded natural frequencies of the deflected configuration are provided by the square root of the eigenvalues. The plot of the loaded natural frequencies vs. corresponding amplitudes in non-dimensional plane represents the backbone curve of the system.

\section{Result and discussion}

Presently, large amplitude forced vibration analysis of AFG Timoshenko beams resting on elastic foundation subjected to transverse harmonic excitation is performed to find out the frequency response of the system in terms of displacement amplitude. In the current study, only steadystate response is presented and frequency of response of the undamped system is assumed to be equal to the forcing frequency. An indirect approach is adopted for solving the problem, where it is reduced to a static scenario by as- suming that under maximum amplitude of excitation, i.e., when the system suffers maximum deformation, the dynamic system satisfies force equilibrium conditions. This assumption converts the dynamic problem into an equivalent static situation, in which the excitation frequency and amplitude of the harmonic excitation are the input parameters that control system response.

Length $(L)$ and width $(b)$ of the beam are taken as 0.2 $\mathrm{m}, 0.02 \mathrm{~m}$, respectively, while, Length-to-thickness ratio $\left(L / t_{0}\right)$ values are varied from 5 to 100 . The length of the beam is fixed throughout the analysis, whereas, the thickness is calculated for each value of Length-to-thickness ratio $\left(L / t_{0}\right)$. It should be noted that the higher values of $L / t_{0}$ correspond to thin beams and are considered here for comparison purpose. Four non-dimensional externally applied time varying excitations $\left[\bar{q}^{*}=\bar{q}\left(L^{4} / E_{0} I_{0} t_{0}\right)\right]$ are considered which are varied from 20 to 60 in equal steps of 10.

For AFG beam, two materials are chosen as Aluminium and Zirconia, and their material properties are: $\mathrm{Al}$ : $E_{0}=70 \mathrm{GPa}, \rho_{0}=2702 \mathrm{~kg} / \mathrm{m}^{3} ; \mathrm{ZrO}_{2}: E_{1}=200 \mathrm{GPa}, \rho_{1}=5700$ $\mathrm{kg} / \mathrm{m}^{3}$. It is also important to note that, for the present AFG beam model, the root side of the beam $(\xi=0)$ is purely Aluminium and continuous gradation is performed along the length to obtain the material property at the other end $(\xi=$ $1)$, which is purely Zirconia. The gradation of the material properties for different gradient parameter $(n)$ are shown in Figure 2. From the figures, it is observed that for $n=1$ linear gradation of the material properties can be obtained, where $50 \%$ of each material (Aluminium/Zirconia) property contribution is observed. Due to this reason, for the best practice gradient parameter $(n)$ beyond 3 and below $1 / 3$ is not considered [48]. Poisson ratio $(\mu)$ with a value of 0.3 is taken as constant throughout the entire analysis.

Four different value of the non-dimensional foundation stiffness parameter $\left[K_{f}=k_{f}\left\{\left(L / t_{0}\right)^{3} / E_{0} b\right\}\right]$ is consider here. These values are $0,20,40$ and 60 respectively. Here, $k_{f}$ is the dimensional value of stiffness.

In the present study, computation is conducted in a normalized domain $(\xi=x / L)$. For generating the computation points for numerical solution within the normalized domain, gauss points $(n g)$ are created along the length of the beam. A detailed convergence study is required for the choice of number of gauss points. Similar study is also applicable for the selection of the number of functions in the assumed displacement field as well. Such a study is necessary as these selections greatly influence the results of the numerical scheme. This convergence study is carried out on CC AFG non-uniform ( $\alpha=0.5$ ) beam with gradient parameter, $n=2$ on an elastic foundation having $K_{f}=$ 10. The comparison of non-dimensional fundamental fre- 


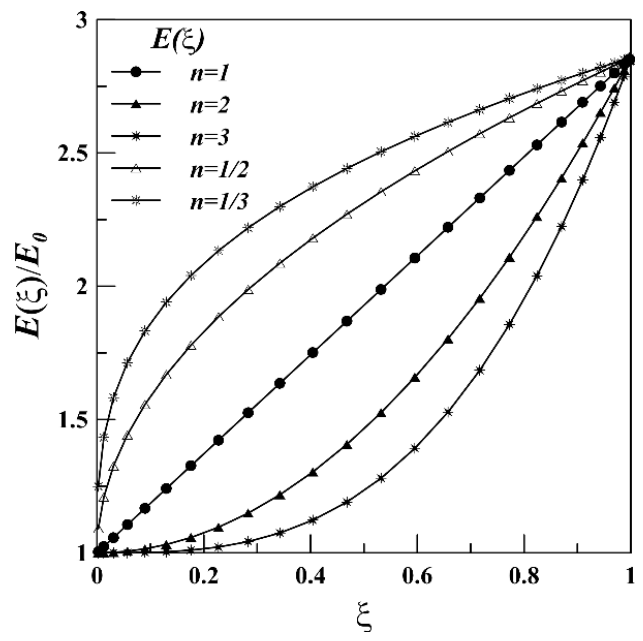

(a)

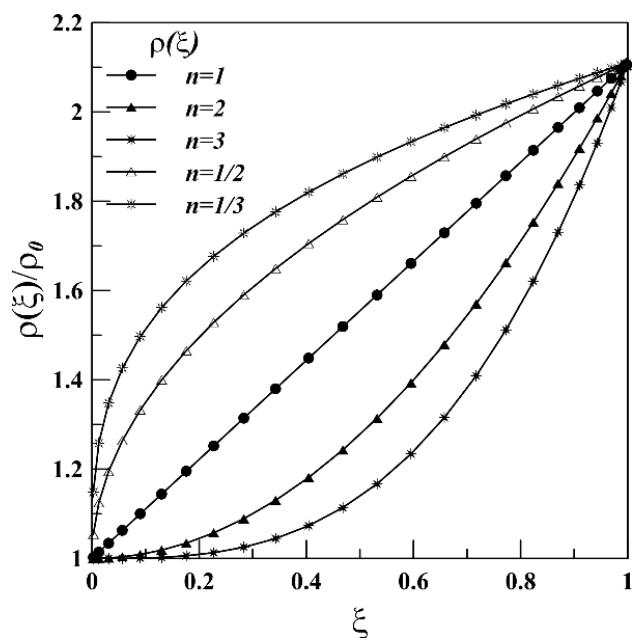

(b)

Figure 2: Axial gradation of material properties (a) Elastic modulus, (b) Density

quency is conducted with respect to the relevant parameters considering no load condition. The results of the study are presented in Figure 3 and from these figures, number of gauss points $(\mathrm{ng})$ and number of orthogonal functions $(n w=n u=n s i)$ are selected as 24 and 8, respectively.

The present methodology and solution procedure is validated with the results of previously published paper of Ribeiro [49] for homogeneous and uniform thick beam without considering elastic foundation. The comparison of linear dimensionless natural frequencies for first five modes are tabulated in Table 2 for CC end conditions. Comparison of the nonlinear frequency response is also shown in Figure 4. For this purpose, the length $(L)$, width (b) and length to thickness ratio $\left(L / t_{0}\right)$ of the beam are taken as $0.406 \mathrm{~m}, 0.02$ and 20, respectively. Elastic modulus $\left(E_{0}\right)$, Density $\left(\rho_{0}\right)$ and Poisson ratio $(\mu)$ are considered as 71.72

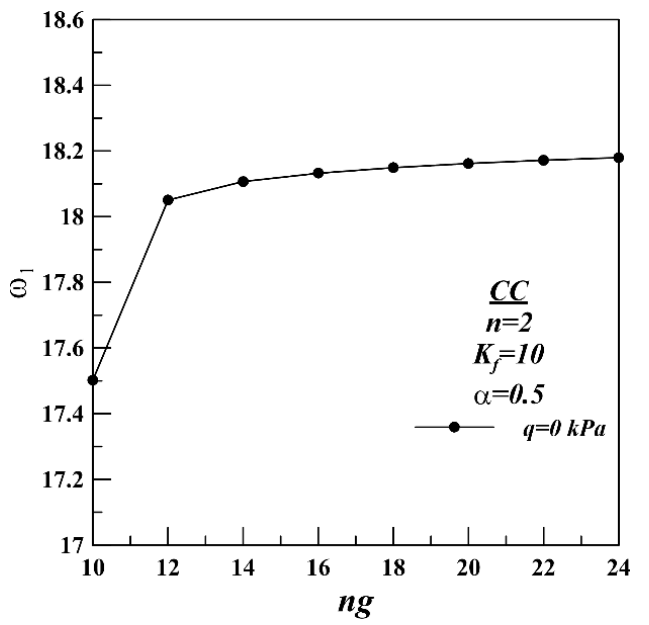

(a)

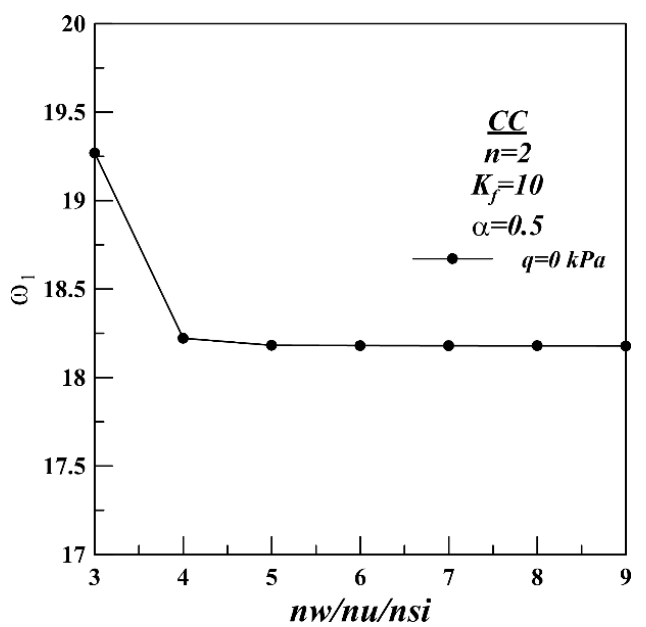

(b)

Figure 3: Convergence study (a) number of gauss points ( $n g$ ), (b) number of orthogonal functions ( $n w=n u=n s i)$

$\mathrm{GPa}, 2800 \mathrm{~kg} / \mathrm{m}^{3}$ and 0.33 respectively. A $2 \mathrm{kN}$ concentrated load is considered at the mid span of the beam. From the above comparison, it can be observed that the current results have satisfactory matching with the established results.

The results are generated for different excitation amplitudes, foundation stiffness, gradation parameters, taper parameters and length to thickness ratio. These results are plotted in a non-dimensional frequency amplitude plane. The abscissa is represented by the non-dimensional frequency $\left(\omega_{f} / \omega_{1}\right)$ and the ordinate represents the dimensionless response amplitude $\left(w_{\max } / t_{0}\right)$. Here, the excitation frequency $\left(\omega_{f}\right)$ is normalized using the fundamental natural frequency $\left(\omega_{1}\right)$, whereas the maximum deflection $\left(w_{\max }\right)$ is normalized using beam root thickness root $\left(t_{0}\right)$. To detect the effect more accurately, results are plotted separately for three different boundary conditions (CC, CS and 
Table 2: Comparisons of dimensionless natural frequencies $\left(\Omega_{1}=\omega_{1} L^{2} \sqrt{\rho_{0} A_{0}} / E_{0} I_{0}\right)$ of homogeneous uniform beam

\begin{tabular}{cccccc}
\hline Literature & $\Omega_{1}$ & $\Omega_{2}$ & $\Omega_{3}$ & $\Omega_{4}$ & $\Omega_{5}$ \\
\hline Ribeiro [49] & 22.0125 & 59.4594 & 113.6121 & 183.3579 & 217.6559 \\
Present Study & 21.9148 & 59.1112 & 112.7598 & 180.4668 & 217.2188 \\
\% Error & 0.44 & 0.58 & 0.75 & 1.5 & 0.2 \\
\hline
\end{tabular}

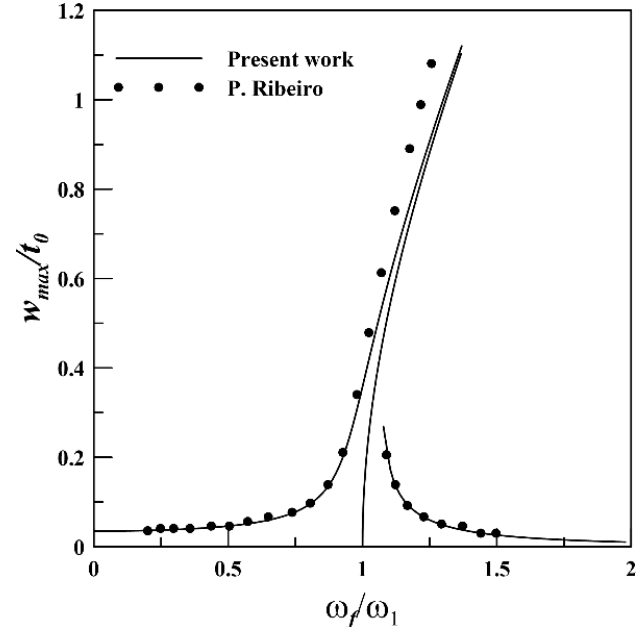

Figure 4: Comparison of nonlinear frequency response

Table 3: First dimensionless $\left(\Omega_{1}=\omega_{1} L^{2} \sqrt{\rho_{0} A_{0}} / E_{0} I_{0}\right)$ natural frequencies of axially graded and non-uniform thick beam on elastic foundation for different foundation stiffness $\left(K_{f}\right)$ considering $L / t_{0}=$ $20, n=2, \alpha=0.5$

\begin{tabular}{lcccc}
\hline BC & \multicolumn{4}{c}{ Foundation Stiffness $\left(K_{f}\right)$} \\
\cline { 2 - 5 } & 0 & 20 & 40 & 60 \\
\hline CC & 17.4861 & 18.8479 & 20.1176 & 21.3118 \\
CS & 12.4992 & 14.3216 & 15.9368 & 17.4027 \\
SS & 7.8575 & 10.5490 & 12.6815 & 14.5037 \\
\hline
\end{tabular}

Table 4: First dimensionless $\left(\Omega_{1}=\omega_{1} L^{2} \sqrt{\rho_{0} A_{0}} / E_{0} I_{0}\right)$ natural frequencies of axially graded and non-uniform thick beam on elastic foundation for different gradient parameter $(n)$ considering $L / t_{0}=$ 20, $K_{f}=10, \alpha=0.5$

\begin{tabular}{llllll}
\hline BC & \multicolumn{5}{c}{ Gradient parameter $(n)$} \\
\cline { 2 - 6 } & $1 / 3$ & $1 / 2$ & 1 & 2 & 3 \\
\hline CC & 18.1331 & 17.9085 & 17.8151 & 18.1798 & 18.4563 \\
CS & 13.8023 & 13.5641 & 13.3417 & 13.4413 & 13.5562 \\
SS & 9.4313 & 9.4069 & 9.3503 & 9.3011 & 9.2918 \\
\hline
\end{tabular}

SS) which are shown in different sub-plots under the figure caption (a), (b) and (c).

To obtain the frequency response plots frequency sweep is initiated at zero excitation frequency with a par-
Table 5: First dimensionless $\left(\Omega_{1}=\omega_{1} L^{2} \sqrt{\rho_{0} A_{0}} / E_{0} I_{0}\right)$ natural frequencies of axially graded and non-uniform thick beam on elastic foundation for different taper parameter $(\alpha)$ considering $L / t_{0}=20$, $K_{f}=10, \mathrm{n}=2$

\begin{tabular}{lcccc}
\hline BC & \multicolumn{4}{c}{ Taper parameter $(\alpha)$} \\
\cline { 2 - 5 } & 0.0 & 0.2 & 0.4 & 0.6 \\
\hline CC & 24.6796 & 22.1867 & 19.5582 & 16.7477 \\
CS & 16.0843 & 15.0841 & 14.0113 & 12.8443 \\
SS & 11.3748 & 10.4817 & 9.6674 & 8.9706 \\
\hline
\end{tabular}

Table 6: First dimensionless $\left(\Omega_{1}=\omega_{1} L^{2} \sqrt{\rho_{0} A_{0}} / E_{0} I_{0}\right)$ natural frequencies of axially graded and non-uniform thick beam on elastic foundation for different Length-to-thickness ratio $\left(L / t_{0}\right)$ considering $\alpha=0.5, K_{f}=10, \mathrm{n}=2$

\begin{tabular}{lcccc}
\hline BC & \multicolumn{4}{c}{ Length-to-thickness ratio $\left(L / t_{0}\right)$} \\
\cline { 2 - 5 } & 5 & 10 & 25 & 100 \\
\hline CC & 16.2471 & 17.7276 & 18.2368 & 18.3334 \\
CS & 12.5017 & 13.2315 & 13.4674 & 13.5112 \\
SS & 9.0525 & 9.2481 & 9.3077 & 9.3206 \\
\hline
\end{tabular}

ticular value of excitation amplitude and increased gradually towards resonance. This type of sweep is termed as forward sweep. Conversely, a backward frequency sweep is carried out by gradually decreasing the excitation frequency from a finite high value.

The effect of excitation amplitude on the frequency response of AFG beam is shown in Figure 5. Three plots for three different boundary conditions (CC, CS and SS) are presented. Foundation stiffness, gradient parameter, length-to-thickness ratio and taper parameter have been fixed at 10, 2, 20 and 0.5, respectively, whereas the nondimensional excitation amplitude is varied from 20 to 50 in steps. It is noted that the normalizing factor for the three boundary conditions are different as shown in Table 4. As the clamped end conditions are replaced by simply supported ends, overall rigidity of the system reduces as evidenced by the lower natural frequencies. It is observed from Figure 5 that at a given excitation frequency, the response amplitude of beam with SS boundary conditions (Figure 5(c)) are the highest, whereas for beam with 


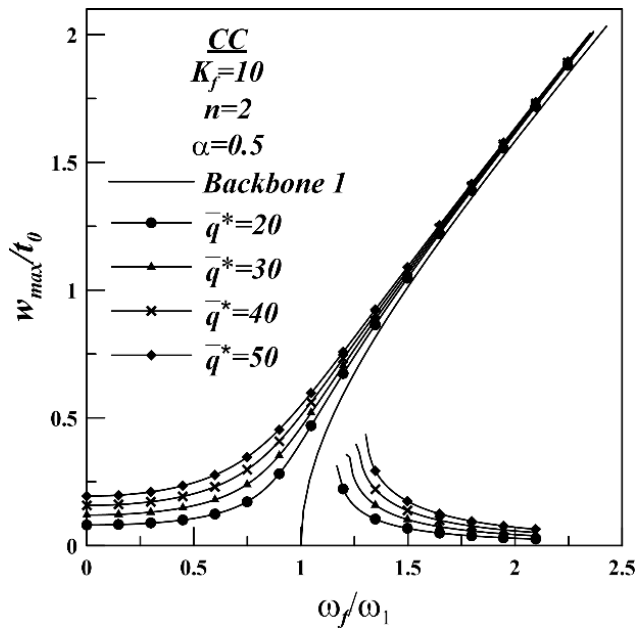

(a)

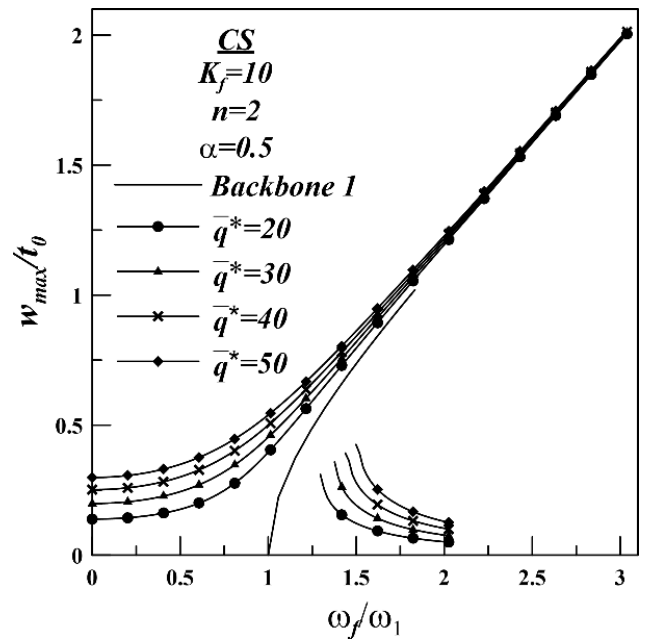

(b)

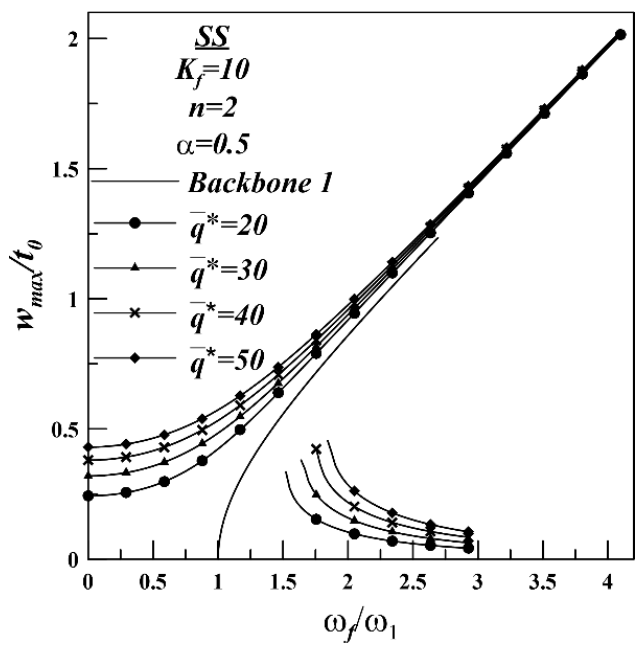

(c)

Figure 5: Effects of the force amplitude on frequency response for (a) CC, (b) CS and (c) SS beam
CC boundary conditions (Figure 5(a)) it is lowest. The figures also show that increasing of the excitation amplitude increases the forced vibration response amplitude of the beam.

It is evident from the figures that the general behaviour of the frequency response curves is similar. In all the cases two separate response branches are visible. In one branch, response amplitude monotonically increases with excitation frequency, while, in the other one it decreases with increase in forcing frequency. Interestingly, after a certain frequency value a multiple response zone is obtained, where, corresponding to one excitation frequency two responses are present. It is also observed that the plots are tilted towards the right of vertical in all three cases. This behaviour can be attributed to the stretching effect associated with large deflection resulting in additional stiffening of the system. Another important observation that can be made from these figures is that, if the excitation amplitude is continuously decreased the amplitude of the response is also going to decrease and at very low excitation amplitude the response curve will tend to almost merge with the backbone curve.

The effect of the foundation stiffness on frequency response is shown in Figure 6. The excitation amplitude, gradient parameter, length-to-thickness ratio and taper parameter have been fixed at 60, 2, 20 and 0.5, respectively. Plots are generated considering four dimensionless foundation stiffness values, which are varied from 0 to 60 . It is to be noted that foundation stiffness value ' 0 ' represents the case where the beam is without any foundation. Table 3 shows that, with the increase in foundation stiffness values fundamental natural frequencies increase in magnitude. The trend can be intuitively attributed to overall increase in stiffness of the system. From the figures, it is clear that, for CC beam (Figure 6(a)) with the increase of the foundation stiffness the response amplitude decreases in the low excitation frequency zone. But the trend is completely opposite in the higher frequency zone. Similar trends can be seen for CS and SS beam (Figures 6(b)6(c)) as well. There appears to be cross-over point in the response behaviour around $\omega_{f} / \omega_{1}=1.00$ in each case. Another important observation is that the response curves of $\mathrm{SS}$ beam are more diverging in the non-dimensional plane from each other than the other two boundaries. Here, with change in foundation stiffness, four different backbone curves would be obtained. These backbone curves are not included in the figures in order to make them less cluttered.

The effects of the gradation parameter on frequency response are shown in Figure 7. The excitation amplitude, foundation stiffness, length-to-thickness ratio and taper 


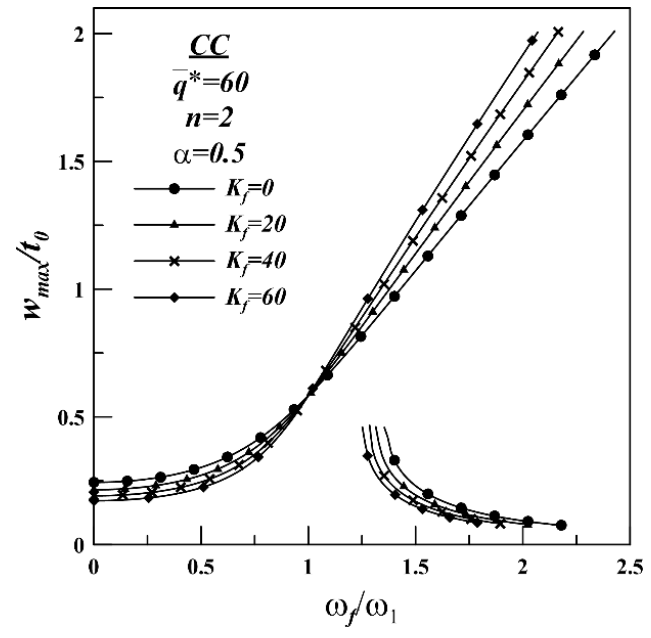

(a)

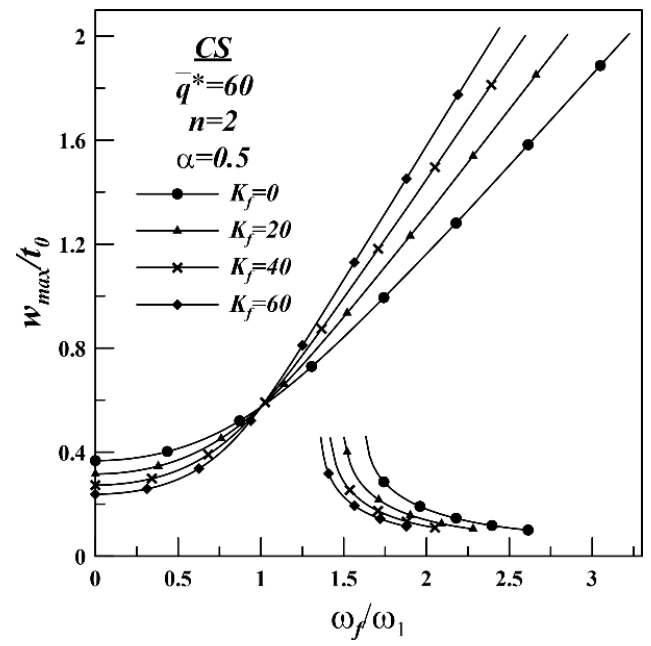

(b)

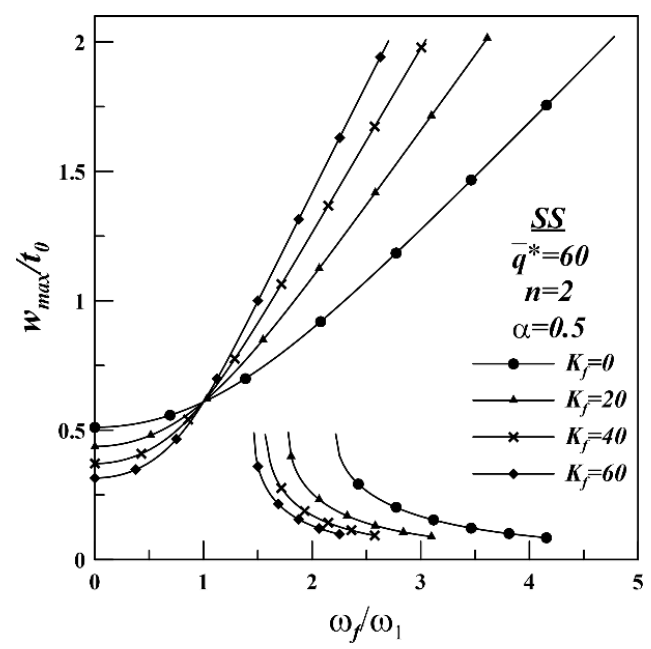

(c)

Figure 6: Effects of the foundation stiffness on frequency response for (a) CC, (b) CS and (c) SS beam parameter have been fixed at 60, 10, 20 and 0.5 respectively. Plots are generated considering five gradation parameter, which are varied from $1 / 3$ to 3 . From the figure, it is observed that in case of CC beam (Figure 7(a)), with the increase of gradation parameter the response amplitude is increasing in nature. Same trend can be found for the CS (Figure 7(b)) and SS beam (Figure 7(c)) as well.

Figure 8 shows the effect of taper parameter on forced vibration response of AFG Timoshenko beam for different boundaries. The excitation amplitude, foundation stiffness, length-to-thickness ratio and gradient parameter have been fixed at 60,10, 20 and 2 respectively. The taper parameter is varied from 0.0 to 0.6 with intermediate values of 0.2 and 0.4 . It is to be noted that taper parameter 0.0 represents the case of uniform beam. From Table 5 it is observed that the fundamental natural frequencies decrease with the increase of taper parameter values. This type of trend is found due to removal of material with increasing taper which further contributes to the reduction of beam stiffness. From the figures, it is observed that with the increase of taper parameter values, the amplitude of the response is increasing in nature in the low frequency domain, whereas, the trend is reversed at higher frequency range. In these sets of figures, the backbone curves for the four individual cases are not incorporated for the sake of better clarity.

The effects of the length-to-thickness ratio on frequency response are shown in Figure 9. The excitation amplitude, foundation stiffness, gradation parameter and taper parameter has been fixed at $60,10,2$ and 0.5 , respectively. Plots are generated considering four different length-to-thickness ratio values, which are 5, 20, 25 and 100. It is important to note that the beam with lengthto-thickness ratio value 5 indicates that it is a very thick beam, whereas beam with length-to-thickness ratio value 100 resembles as a very thin beam. From Table 6, it is observed that the fundamental frequency increases with the increase of length-to-thickness ratio value. From Figure 9, it is noted that, with the increase of length-to-thickness ratio value, the response amplitude is decreasing in nature for all three boundary conditions. In case of CC beam (Figure 9(a)) the effect is more prominent than the other two. CS beam shows the moderate effect (Figure 9(b)), whereas this is negligible for SS beam, in which all the branches of curves for four different length-to-thickness ratio values are coinciding as a single curve (Figure 9(c)). However, it is important to keep in mind that these trends are obtained in the non-dimensional plane. In terms of dimensional values there is bound to be sufficient differences between the curves corresponding to different length to thickness ratios. 


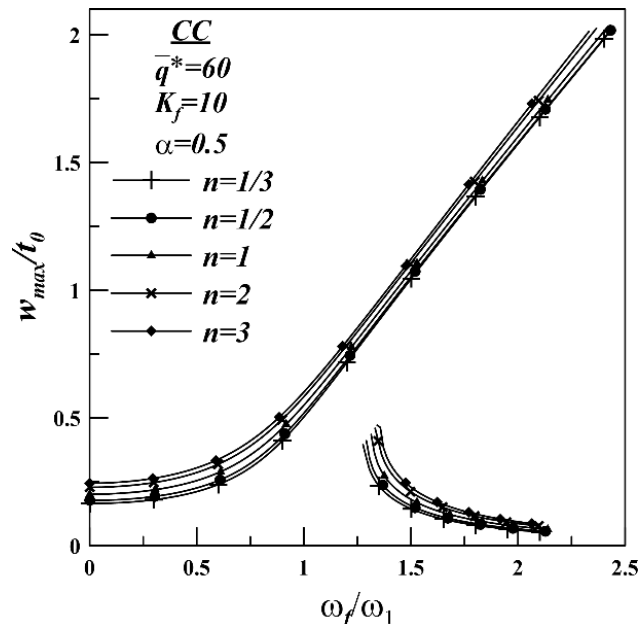

(a)

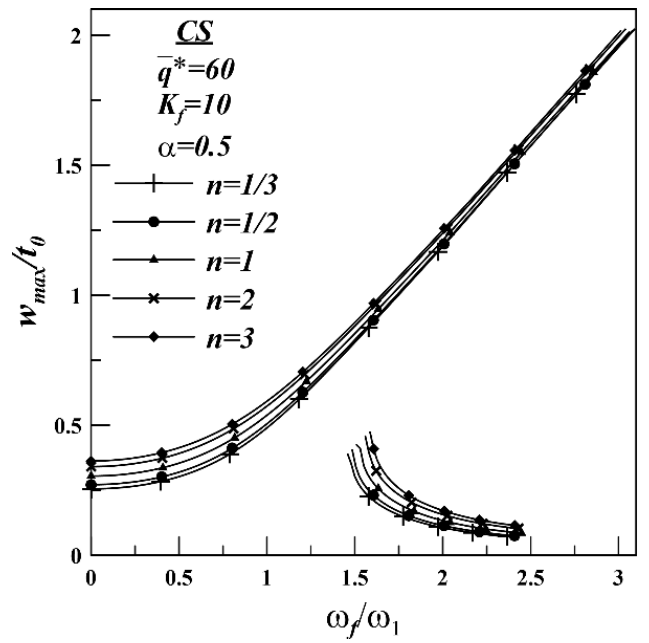

(b)

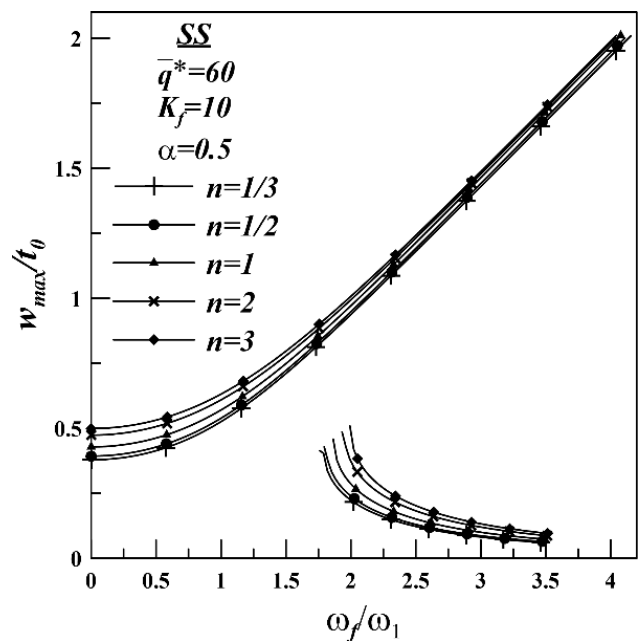

(c)

Figure 7: Effects of the gradation index on frequency response for (a) CC, (b) CS and (c) SS beam

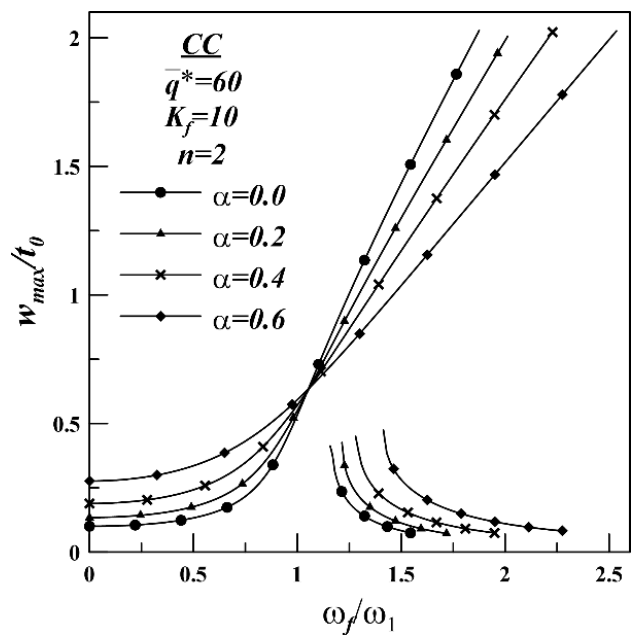

(a)

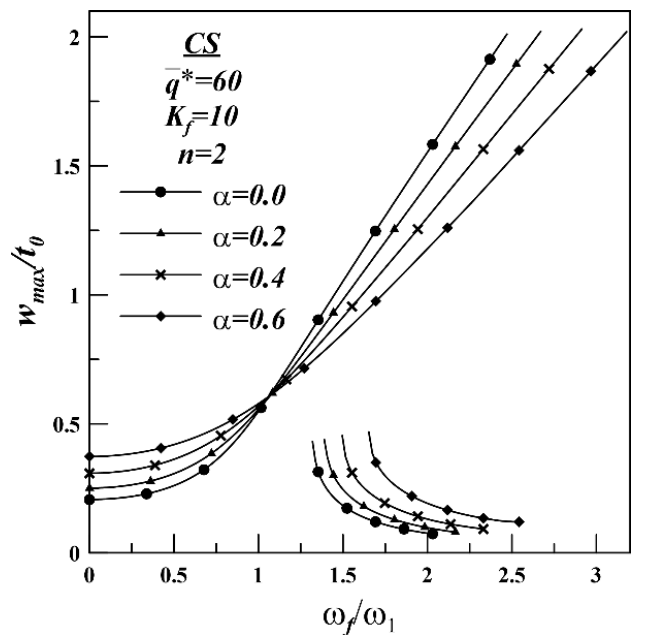

(b)

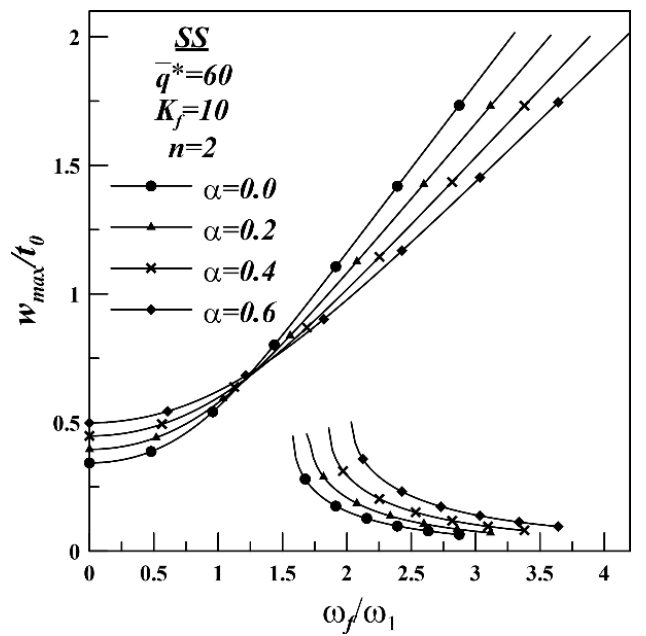

(c)

Figure 8: Effects of the taper parameter on frequency response for (a) CC, (b) CS and (c) SS beam 


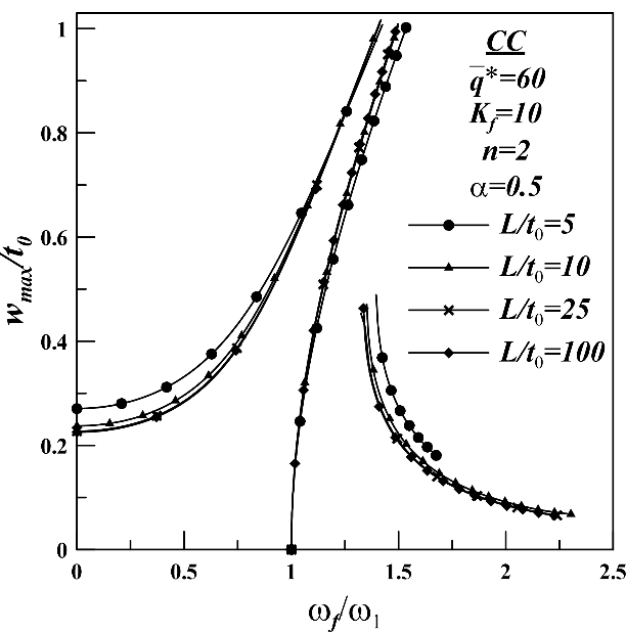

(a)

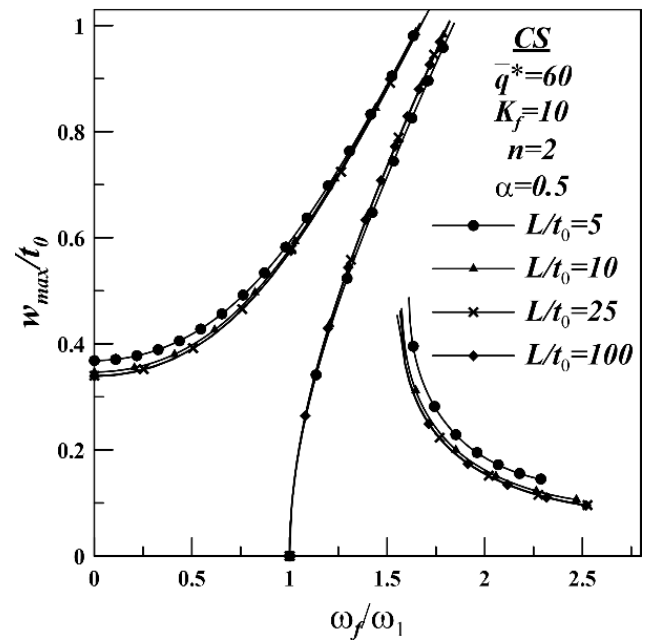

(b)

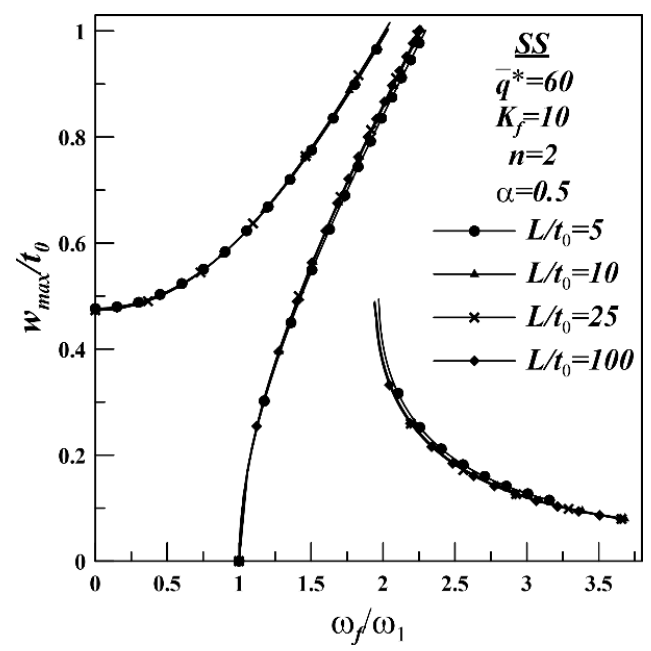

(c)

Figure 9: Effects of the length-to-thickness ratio on frequency response for (a) CC, (b) CS and (c) SS beam

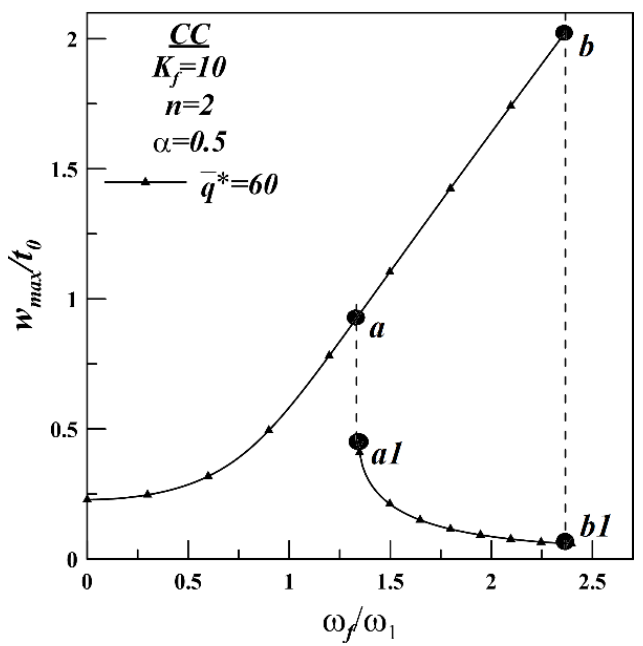

(a)

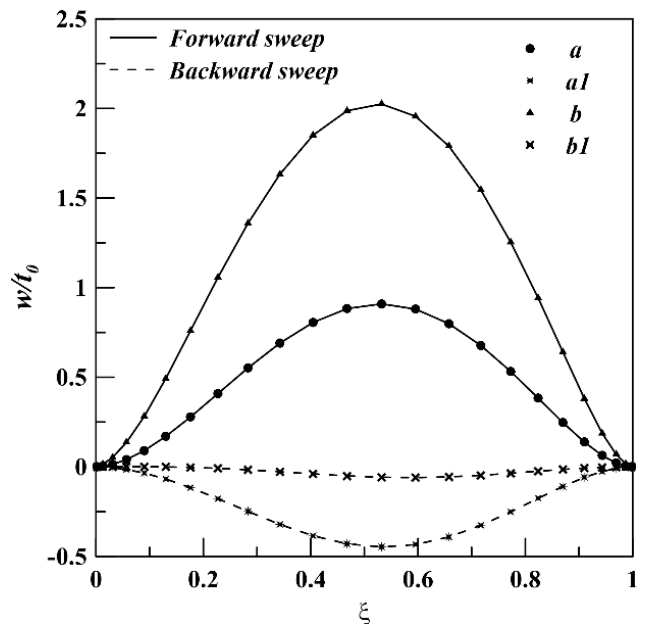

(b)

Figure 10: Operational deflected shape (ODS) (a) nonlinear frequency response with representative point, (b) deflected shape of the corresponding points

From the Figures 5-9, the frequency response curves are categorized by two distinct zones. In the first zone, with the increase in excitation frequency, the response amplitude increases, while, in the other zone response amplitude reduces. Nonlinear behaviour of the system can be observed in the Multi response zone where two response amplitudes corresponding to the previously mentioned distinct zones are found. The branches of the response curve in these two zones are stable solutions. Theoretically, a third zone, where an unstable steady-state solution is possible, exists but cannot be captured through current methodology.

The effects of excitation frequency on the operational deflected shape (ODS) is studied and furnished in Figure 10. For that purpose, a CC beam is considered 
with taper parameter of 0.5. The excitation amplitude, foundation stiffness, length-to-thickness ratio and gradient parameter have been fixed at 60,10, 20 and 2, respectively. Figure 10(a) shows the representative points on the frequency-response curve at different frequencyamplitude combinations. On the increasing curve, the start of the multi-response zone is denoted by point ' $a$ ' and point ' $b$ ' represents the point at $w_{\max } / t_{0}=2$. Point 'a1' and 'b1' are obtained on the same excitation frequency level as ' $a$ ' and 'b' respectively but on lower curve. The operational deflected shape corresponding to these representative points are shown in Figure 10(b). The ODS corresponding to different representative points appear similar in nature but with different maximum response amplitude. However, one major issue can be noted that the response at the lower branch is out of phase with the response in the upper branch.

\section{Conclusion}

In the present study, forced vibration analysis under harmonic excitation is conducted on axially functionally graded non-uniform Timoshenko beam on elastic foundation. The nonlinear dynamic frequency response is studied considering nonlinear strain displacement relationship. The effects of shear deformation and rotary inertial taken into consideration following Timoshenko beam theory. Three different classical boundary conditions (CC, CS and SS) are considered along with the linear elastic foundation support. The formulation is able to handle other type of classical boundary condition, elastic foundation support and excitation pattern with minor modifications. A displacement based semi-analytical approximate method is utilized for the mathematical formulation and the governing set of the equations is obtained by using Hamilton's principle. For the numerical solution of the governing set of the nonlinear equations, a quasiNewton method, known as Broyden's method, is implemented. For the proper selection of different parameters for the numerical solution detailed convergence study is performed. The present methodology and the solution procedure are successfully validated with the previously existing results from literature. The effects of the excitation amplitude, foundation stiffness, gradient parameter, taper parameter and length-to-thickness ratio on frequency response curves are plotted in non-dimensional plane to serve as benchmark results.

\section{References}

[1] Goupee AJ and Vel SS 2006 Optimization of natural frequencies of bidirectional functionally graded beams Struct Multidisc Optim 32 473-484

[2] Simsek M 2016 Buckling of Timoshenko beams composed of two-dimensional functionally graded material 2D-FGM having different boundary conditions Compos Struct 149 304-314

[3] Huynh TA, Lieu XQ and Lee J 2017 NURBS-based modeling of bidirectional functionally graded Timoshenko beams for free vibration problem Compos Struct 160 1178-1190

[4] Karamanlı A 2018 Free vibration analysis of two directional functionally graded beams using a third order shear deformation theory Compos Struct 189 127-136

[5] Khaniki HB and Rajasekaran S 2018 Mechanical analysis of nonuniform bi-directional functionally graded intelligent microbeams using modified couple stress theory Mater Res Express. 5055703 https://doi org/10 1088/2053-1591/aabe62

[6] Kadoli R, Akhtar K and Ganesan N 2008 Static analysis of functionally graded beams using higher order shear deformation theory Appl Math Model. 32 2509-2525

[7] Hemmatnezhad M, Ansari R and Rahimi GH 2013 Largeamplitude free vibrations of functionally graded beams by means of a finite element formulation Appl Math Model. 37 8495-8504

[8] Pradhan KK and Chakraverty S 2014 Effects of different shear deformation theories on free vibration of functionally graded beams Int J Mech Sci 82 149-160

[9] Chen D, Yang J and Kitipornchai S 2015 Elastic buckling and static bending of shear deformable functionally graded porous beam Compos Struct 133 54-61

[10] Ebrahimi F and Zia M 2015 Large amplitude nonlinear vibration analysis of functionally graded Timoshenko beams with porosities Acta Astronaut. 116 117-125

[11] Paul A and Das D 2016 Free vibration analysis of pre-stressed FGM Timoshenko beams under large transverse deflection by a variational method Eng. Sci. Technol. Int J. 19 1003-1017

[12] Aydogdu M 2008 Semi-inverse method for vibration and buckling of axially functionally graded beams J. Reinf. Plast. Compos 27(7) 683-691

[13] Shahba A, Attarnejad R and Hajilar S 2011 Free vibration and stability of axially functionally graded tapered Euler-Bernoulli beams Shock Vib. 18 683-696

[14] Alshorbagy AE, Eltaher MA and Mahmoud FF 2011 Free vibration characteristics of a functionally graded beam by finite element method Appl Math Model.35 412-425

[15] Shahba A and Rajasekaran S 2012 Free vibration and stability of tapered Euler-Bernoulli beams made of axially functionally graded materials Appl Math Model.36 3094-3111

[16] Simsek M, Kocatürk T and Akbas SD 2012 Dynamic behavior of an axially functionally graded beam under action of a moving harmonic load Compos Struct 94 2358-2364

[17] Akgöz B and Civalek Ö 2013 Free vibration analysis of axially functionally graded tapered Bernoulli-Euler microbeams based on the modified couple stress theory Compos Struct 98 314-322

[18] Kumar S, Mitra A and Roy H 2015 Geometrically nonlinear free vibration analysis of axially functionally graded taper beams Eng. Sci. Technol. Int J. 18 579-593 
[19] Ghayesh MH and Farokhi H 2018 Bending and vibration analyses of coupled axially functionally graded tapered beams Nonlinear Dyn 9117-28

[20] Rajasekaran S and Khaniki HB 2018 Finite element static and dynamic analysis of axially functionally graded nonuniform smallscale beams based on nonlocal strain gradient theory Mech Adv Mater Struc 0 (0) 1-15

[21] Sınıra S, Çevik M and Sınır BG 2018 Nonlinear free and forced vibration analyses of axially functionally graded Euler-Bernoulli beams with non-uniform cross-section Composites Part B 148 123-131

[22] Shames IH and Dym CL 2009 Energy and Finite Element Methods in Structural Mechanics New Age International Publishers Delhi

[23] Shahba A, Attarnejad R, Marvi MT and Hajilar S 2011 Free vibration and stability analysis of axially functionally graded tapered Timoshenko beams with classical and non-classical boundary conditions Composites: Part B 42 801-808

[24] Huang Y, Yang LE and Luo QZ 2013 Free vibration of axially functionally graded Timoshenko beams with non-uniform crosssection Composites: Part B 45 1493-1498

[25] Huang Y, Zhang M and Rong H 2016 Buckling analysis of axially functionally graded and non-uniform beams based on Timoshenko theory Acta Mech Solida Sin. 29 (2) 200-207

[26] Rajasekaran S 2013 Free vibration of centrifugally stiffened axially functionally graded tapered Timoshenko beams using differential transformation and quadrature methods Appl Math Model.37 4440-4463

[27] Sarkar K and Ganguli R 2014 Closed-form solutions for axially functionally graded Timoshenko beams having uniform crosssection and fixed-fixed boundary condition Composites: Part B 58 361-370

[28] Calim FF 2016 Transient analysis of axially functionally graded Timoshenko beams with variable cross-section Composites Part B 98 472-483

[29] Shafiei N, Kazemi M and Ghadiri M 2016 Comparison of modelling of the rotating tapered axially functionally graded Timoshenko and Euler-Bernoulli microbeams Physica E 83 74-87

[30] Chen DQ, Sun DL, and Li XF 2017 Surface effects on resonance frequencies of axially functionally graded Timoshenko nanocantilevers with attached nanoparticle Compos Struct 173 116-126

[31] Ghayesh MH 2018 Nonlinear vibrations of axially functionally graded Timoshenko tapered beams J Comput Nonlin Dyn. 13 041002-1-10

[32] Huang Y, Wang T, Zhao Y and Wang P 2018 Effect of axially functionally graded material on whirling frequencies and critical speeds of a spinning Timoshenko beam Compos Struct 192 355-367

[33] Mohanty SC, Dash RR and Rout T 2011 Parametric instability of a functionally graded Timoshenko beam on Winkler's elastic foundation Nucl Eng Des. 241 2698-2715

[34] Yan T, Kitipornchai S, Yang J and He XQ 2011 Dynamic behaviour of edge-cracked shear deformable functionally graded beams on an elastic foundation under a moving load Compos Struct 93 2992-3001
[35] Yas MH and Samadi N 2012 Free vibrations and buckling analysis of carbon nanotube-reinforced composite Timoshenko beams on elastic foundation Int J Pres Ves Pip. 98 119-128

[36] Esfahani SE, Kiani Y, and Eslami MR 2013 Non-linear thermal stability analysis of temperature dependent FGM beams supported on non-linear hardening elastic foundations Int J Mech Sci 69 $10-20$

[37] Komijani M, Esfahani SE, Reddy JN, Liu YP and Eslami MR 2014 Nonlinear thermal stability and vibration of pre/postbuckled temperature- and microstructure-dependent functionally graded beams resting on elastic foundation Compos Struct 112 292-307

[38] Tossapanon P and Wattanasakulpong N 2016 Stability and free vibration of functionally graded sandwich beams resting on twoparameter elastic foundation Compos Struct 142 215-225

[39] Deng H, Chen KD, Cheng W and Zhao SG 2017 Vibration and buckling analysis of double-functionally graded Timoshenko beam system on Winkler-Pasternak elastic foundation Compos Struct 160 152-168

[40] Arefi M and Zenkour AM 2017 Wave propagation analysis of a functionally graded magneto-electro-elastic nanobeam rest on Visco-Pasternak foundation Mech. Res. Commun. 79 51-62

[41] Arefi M and Zenkour AM 2017 Analysis of wave propagation in a functionally graded nanobeam resting on visco-Pasternak's foundation Theoret. Applied Mech. Lett. 7 145-151

[42] Huang Y and Luo QZ 2011 A simple method to determine the critical buckling loads for axially inhomogeneous beams with elastic restraint Comput Math Appl. 61 2510-2517

[43] Lohar H, Mitra A and Sahoo S 2016 Geometric nonlinear free vibration of axially functionally graded non-uniform beams supported on elastic foundation Curved and Layer. Struct. 3(1) 223239

[44] Lohar H, Mitra A and Sahoo S 2016 Natural frequency and mode shapes of exponential tapered AFG beams on elastic foundation International Frontier Science Letters 9 9-25

[45] Lohar H, Mitra A and Sahoo S 2018 Geometrically non-linear frequency response of axially functionally graded beams resting on elastic foundation under harmonic excitation International Journal of Manufacturing Materials and Mechanical Engineering 8(3) 23-43

[46] Calim FF 2016 Free and forced vibration analysis of axially functionally graded Timoshenko beams on two-parameter viscoelastic foundation Composites Part B 103 98-112

[47] Press WH, Teukolsky SA, Vetterling WT and Flannery BP 2005 Numerical Recipes in Fortran 77 2nd ed Cambridge USA: Press Syndicate

[48] Nakamura T, Wang T and Sampath S 2000 Determination of properties of graded materials by inverse analysis and instrumented indentation Acta Mater. 48 1444-1450

[49] Ribeiro P 2004 Non-linear forced vibrations of thin/thick beams and plates by the finite element and shooting methods Comput Struct 82 1413-1423 


\section{Appendix}

The elements of the stiffness matrix $\left[K_{i j}\right]$ are:

$$
\begin{aligned}
& {\left[K_{i j}\right]_{\substack{i=1, n w \\
j=1, n w}}=\frac{b}{2} \int_{0}^{L}\left(\sum_{k=1}^{n w} d_{k} \frac{d \phi_{k}}{d x}\right)^{2} \frac{d \phi_{i}}{d x} \frac{d \phi_{j}}{d x} t(x) E(x) d x} \\
& +b \int_{0}^{L}\left(\sum_{k=n w+1}^{n w+n u} d_{k} \frac{d \alpha_{k-n w}}{d x}\right) \frac{d \phi_{i}}{d x} \frac{d \phi_{j}}{d x} t(x) E(x) d x \\
& +k_{s h} b \int_{0}^{L} \frac{d \phi_{i}}{d x} \frac{d \phi_{j}}{d x} t(x) G(x) d x \\
& {\left[K_{i j}\right]_{\substack{i=1, n w \\
j=n w+1, n w+n u}}=0} \\
& {\left[K_{i j}\right] \underset{\substack{i=1, n w \\
j=n w+n u+1, n w+n u+n s i}}{=}=} \\
& -k_{s h} b \int_{0}^{L} \frac{d \phi_{i}}{d x} \beta_{j-n w-n u} t(x) G(x) d x \\
& {\left[K_{i j}\right]_{\substack{i=n w+1, n w+n u \\
j=1, n w}}=} \\
& \frac{b}{2} \int_{0}^{L}\left(\sum_{k=1}^{n w} d_{k} \frac{d \phi_{k}}{d x}\right) \frac{d \alpha_{i-n w}}{d x} \frac{d \phi_{j}}{d x} t(x) E(x) d x \\
& {\left[K_{i j}\right]_{\substack{i=n w+1, n w+n u \\
j=n w+1, n w+n u}}=b \int_{0}^{L} \frac{d \alpha_{i-n w}}{d x} \frac{d \alpha_{j-n w}}{d x} t(x) E(x) d x} \\
& {\left[K_{i j}\right]_{\substack{i=n w+1, n w+n u \\
j=n w+n u+1, n w+n u+n s i}}=0} \\
& {\left[K_{i j}\right]_{\substack{i=n w+n u+1, n w+n u+n s i \\
j=1, n w}}=} \\
& -k_{s h} b \int_{0}^{L} \beta_{i-n w-n u} \frac{d \phi_{j}}{d x} t(x) G(x) d x \\
& {\left[K_{i j}\right]_{\substack{i=n w+n u+1, n w+n u+n s i \\
j=n w+1, n w+n u}}=0} \\
& {\left[K_{i j}\right]_{i=n w+n u+1, n w+n u+n s i}=} \\
& \frac{b}{12} \int_{0}^{L} \frac{d \beta_{i-n w-n u}}{d x} \frac{d \beta_{j-n w-n u}}{d x} t^{3}(x) E(x) d x
\end{aligned}
$$

$$
+k_{s h} b \int_{0}^{L} \beta_{i-n w-n u} \beta_{j-n w-n u} t(x) G(x) d x
$$

The elements of the mass matrix $\left[M_{i j}\right]$ are,

$$
\begin{gathered}
{\left[M_{i j}\right]_{\substack{i=1, n w \\
j=1, n w}}=b \int_{0}^{L} \phi_{i} \phi_{j} t(x) \rho(x) d x} \\
{\left[M_{i j}\right]_{\substack{i=n w+1, n w+n u \\
j=n w+1, n w+n u}}=b \int_{0}^{L} \alpha_{i-n w} \alpha_{j-n w} t(x) \rho(x) d x} \\
{\left[M_{i j}\right]_{\substack{i=n w+n u+1, n w+n u+n s i \\
j=n w+n u+1, n w+n u+n s i}}^{L}} \\
\frac{b}{12} \int_{0}^{L} \beta_{i-n w-n u} \beta_{j-n w-n u} t^{3}(x) \rho(x) d x
\end{gathered}
$$

Rest all other elements of the mass matrix $\left[M_{i j}\right]$ are zero.

The elements of the load vector $\left\{f_{i}\right\}$ are,

$$
\begin{gathered}
\left\{f_{i}\right\}_{i=1, n w}=q \int_{0}^{L} \phi_{i} d x \\
\left\{f_{i}\right\}_{i=n w+1, n w+n u}=0 \\
\left\{f_{i}\right\}_{i=n w+n u+1, n w+n u+n s i}=0
\end{gathered}
$$

